\title{
Polymer Catalysts Imprinted with Metal Ions as Biomimics of Metalloenzymes
}

\author{
Joanna Czulak, Anna Jakubiak-Marcinkowska, and Andrzej Trochimczuk \\ Department of Polymer and Carbonaceous Materials, Faculty of Chemistry, Wroclaw University of Technology, \\ Wybrzeze Wyspianskiego 27, 50-370 Wroclaw, Poland \\ Correspondence should be addressed to Joanna Czulak; joanna.czulak@pwr.wroc.pl
}

Received 15 March 2013; Accepted 2 July 2013

Academic Editor: Ibrahim Narin

Copyright (C) 2013 Joanna Czulak et al. This is an open access article distributed under the Creative Commons Attribution License, which permits unrestricted use, distribution, and reproduction in any medium, provided the original work is properly cited.

This work presents the preparation and properties of molecularly imprinted polymers (MIPs) with catalytic centers that mimic the active sites of metalloenzymes. The MIP synthesis was based on suspension polymerization of functional monomers (4vinylpyridine and acrylonitrile) with trimethylolpropane trimethacrylate as a crosslinker in the presence of transition metal ions and 4-methoxybenzyl alcohol as a template. Four metal ions have been chosen for imprinting from among the microelements that are the most essential in the native enzymes: $\mathrm{Cu}^{2+}, \mathrm{Co}^{2+}, \mathrm{Mn}^{2+}$, and $\mathrm{Zn}^{2+}$. To prepare catalysts, the required loading of metal ions was obtained during sorption process. The catalysts imprinted with $\mathrm{Cu}^{2+}, \mathrm{Co}^{2+}$, and $\mathrm{Zn}^{2+}$ were successfully used for hydroquinone oxidation in the presence of hydrogen peroxide. The $\mathrm{Mn}^{2+}$-imprinted catalyst showed no activity due to the insufficient metal loading. $\mathrm{Cu}^{2+} \mathrm{MIP}$ showed the highest efficiency. In case of $\mathrm{Cu}$ - and Co-MIP catalysts, their activity was additionally increased by the use of surface imprinting technique.

\section{Introduction}

The majority of chemical reactions used in the industry are catalyzed reactions. This is the reason why a lot of effort are devoted to synthesize new catalysts and improve the already known catalytic systems. At the same time, a constant tendency to adapt the "green chemistry technology" has been observed. In the chemical synthesis and catalysis, this means improvement of the catalytic system in a way that allows reactions to be performed at the lowest possible temperature, without a solvent or in an environmentally friendly solvent with very high yield and selectivity. Enzymes are found to be favorable materials that comply with these requirements due to the variety of catalyzed reactions, which can be performed close to the room temperature and with high selectivity. Nowadays enzymes are widely used in the food industry and beyond it $[1,2]$.

However, the use of the enzymes is strongly limited due to their sensibility to extreme $\mathrm{pH}$, solvent, and temperature conditions and due to complicated, time-consuming isolation procedures causing high costs [3]. Although these drawbacks can be reduced by immobilization of the proteins on insoluble carriers, it is usually associated with a reduction of both activity and stability of carrier-enzyme system during its application. Favorable solution, to the problem are the artificial enzymes analogues, which do not exhibit the native enzyme's defects but will work with similar efficiency and selectivity. One of the most promising methods for preparation of materials with high recognition ability is molecular imprinting technique. Briefly, the molecular imprinting process consists of polymerization of functional monomers with crosslinker in the presence of the template and porogenic solvent. Subsequently, the template is removed from the polymeric matrix, resulting in three-dimensional cavities complementary in shape and chemical functionality to the binding template molecule (Figure 1).

Monomers used during imprinting can be divided into acidic, basic, and as neutral ones and selection of the appropriate functional monomer is done based on the type of the used template and targeted molecules. The crosslinker plays a crucial role in obtaining desired physicochemical properties and morphology of the polymer matrix. Different 


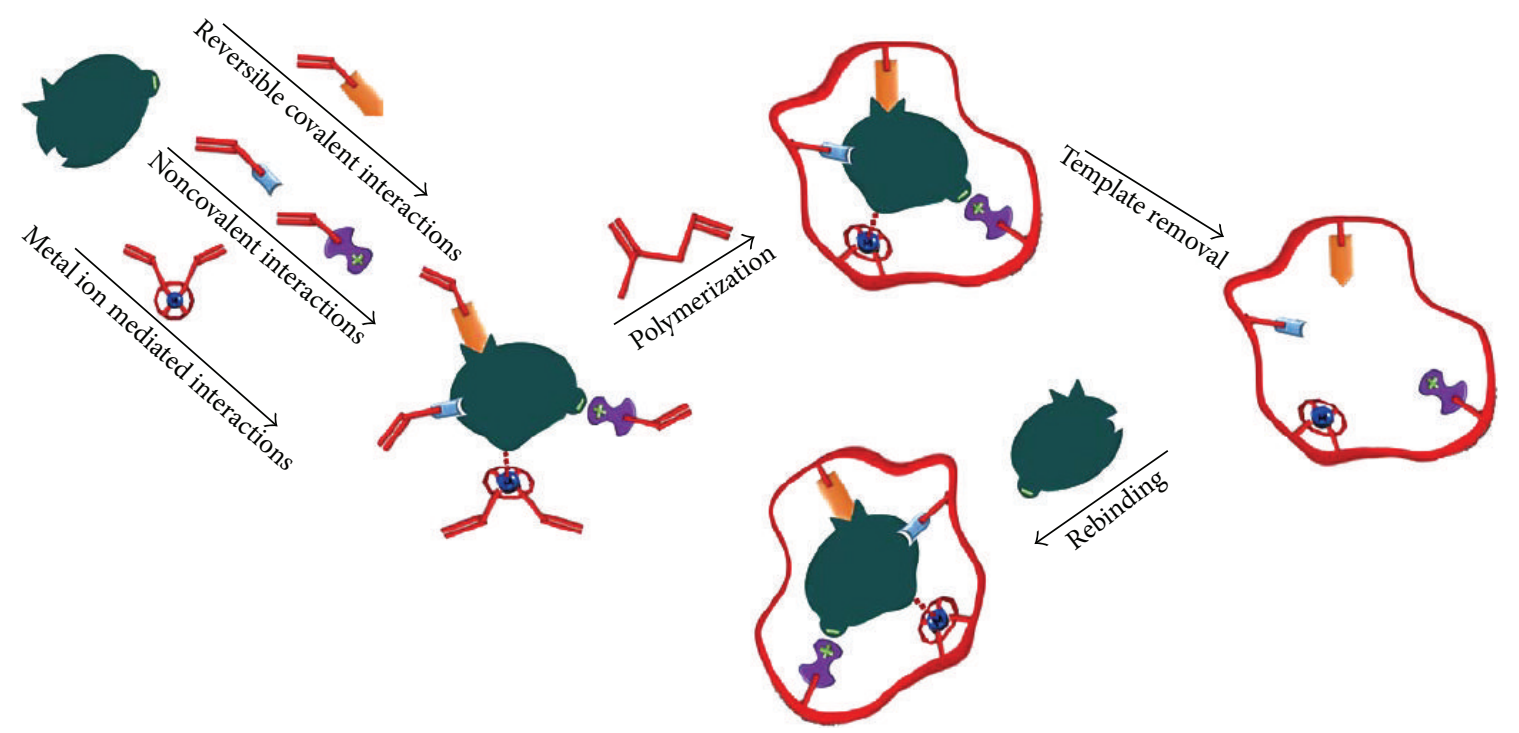

FIgURE 1: Molecular imprinting technique.

crosslinkers to monomer ratio can result in various surface area, pore volume and diameter, and the rigidity of the polymer matrix $[4,5]$. Another advantage of MIPs is a huge number of templates that can be used in imprinting. Template enables proper positioning of monomer's functional groups in the cavities. The solvents which are not directly involved in the polymerization reaction (porogens) affect the imprinting process, the physical structure of the polymer, and the characteristics of MIPs (pore structure, pore size distribution, swelling, morphology, toughness) [6]. Molecularly imprinted polymers (MIPs) found applications in various areas such as separation science, biosensors, drug delivery, chromatography, extraction, and catalysis [6, 7]. Nowadays in the literature there are many reviews about molecularly imprinted polymers, their synthesis, and applications [8-12].

Depending on the used components and the reaction conditions, different types of interactions between template and monomer functional groups in the cavities such as covalent, noncovalent, electrostatic, or metal ion coordination can be obtained. MIPs possessing the ability of fast rebinding are usually prepared using rapidly reversible covalent interactions and/or weaker noncovalent interactions [13]. In case of native enzymes, many of the active centers contain metal ions inside of the cavities that provide better binding rate and higher catalytic activity (Figure 2) [14]. Catalytic systems being a combination of transition metal ions immobilized on synthetic carriers with imprinting materials were found to be very similar to those existing in metalloenzymes. Additionally, stronger stabilization of the transition state than the substrate ground state or product may prevent active side inhibition [15]. Nowadays, two main approaches in creating MIPs with catalytic activity are used. The first one involves introduction of catalytically active functional groups capable of uptake the substrate into the polymerization mixture and finally into the cavity of the polymer. The second one is based on the immobilization of metal or metal complex of

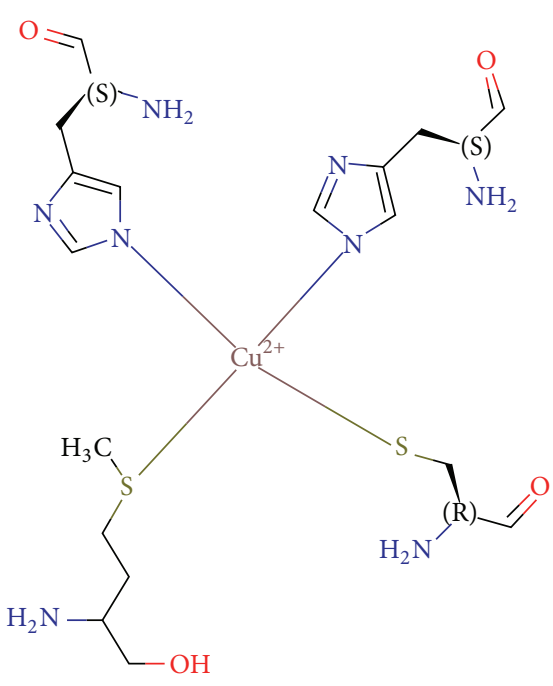

FIgURE 2: Scheme of T1 copper sites of laccase CotA from Bacillus subtilis.

low molecular weight exhibiting catalytic properties [16, 17]. In this method, a significant increase in the selectivity and activity of the resulting enzymes' biomimics is achieved. In addition, in the proximity of the metal ions (metalcomplex), cavities able to capture substrate are formed through the imprinting of metal-complex template (Figure 3). Polymeric enzymes analogues are used in many reactions such as hydrolysis reactions, Diels-Alder aldol condensation, isomerization, and stereoselective reactions, and regioselective reactions $[3,5,8,18-20]$.

Recently, to overcome some limitations associated with cavities availability for template molecules in porous polymer matrices, the new molecular surface imprinting technique has been used. In this technique, MIPs are prepared using 


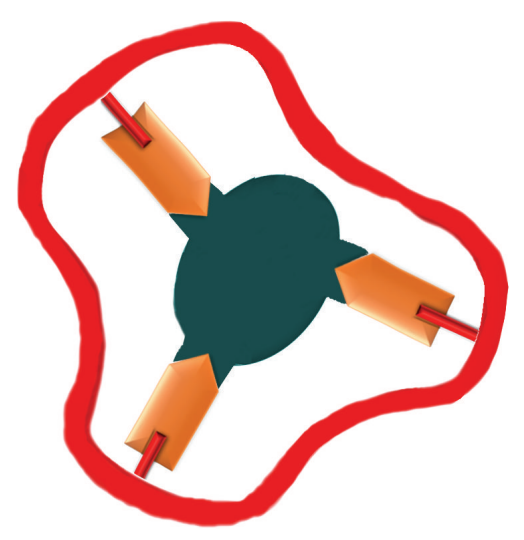

(a)

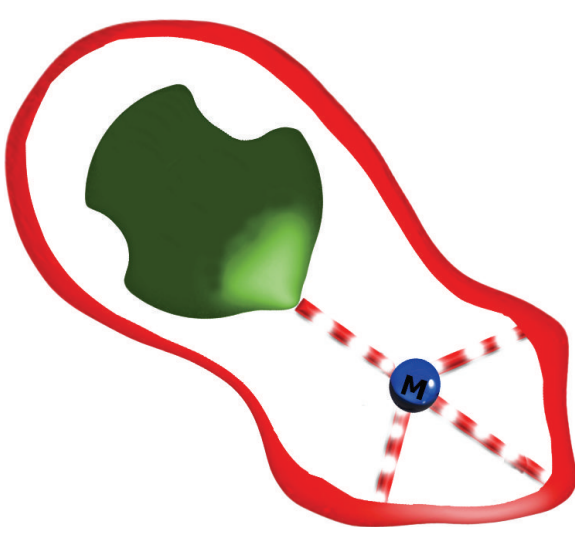

(b)

FIGURE 3: Approaches to creations of MIPs with catalytic activity: (a) introduction of catalytically active functional groups into the cavities and (b) the immobilization of metal or metal complex inside cavities.

water in oil emulsion in the presence of additional functional monomer with high surface activity [21], which leads to the creation of the cavities at the surface of polymer and thus shortening the diffusion time.

\section{Experimental}

2.1. Preparation of Polymers Imprinted with Metal Ions. The molecularly imprinted polymers were prepared by suspension polymerization performed in a glass reactor $(1.5 \mathrm{~L})$ with glass stirring rod and two propellers on it. The continuous aqueous phase $(0.7 \mathrm{~L})$ was consisting of $2 \mathrm{wt} . \%$ sodium chloride solution and a stabilizer, poly(vinyl alcohol) (PVA, 1 wt.\% with respect to the amount of organic phase). After purging the mixture with nitrogen, the reaction was carried out for 10 hours in few steps: first hour at $60^{\circ} \mathrm{C}$, second at $70^{\circ} \mathrm{C}$, next two hours at $85^{\circ} \mathrm{C}$, and the last five hours at $95^{\circ} \mathrm{C}$, with stirring set at $240 \mathrm{rpm}$. In this study, two kinds of the cavities were obtained: in the volume ("volume molecularly imprinted polymers"-KO) and on the surface of the polymer matrix ("surface molecularly imprinted polymers"-KP/KPS). Volume molecularly imprinted polymers were prepared from organic phase containing two functional monomers: 4-vinylpyridine (VP, $1.35 \mathrm{~g}$ ) and acrylonitrile (AN, $13.5 \mathrm{~g}$ ), crosslinking monomer-trimethylolpropane trimethacrylate (TMPMA, $10.00 \mathrm{~g})$, cyclohexanol $(\mathrm{CH}, 48 \mathrm{~mL})$ as a porogen, template4-methoxybenzyl alcohol (MBA, $1.73 \mathrm{~g}$ ), metal ions (as a metal acetate, $2.75 \mathrm{mmol}$ ), and 2,2-azobisisobutyronitrile (AIBN, $1 \mathrm{~g}$ ). In the case of surface molecularly imprinted polymers, W/O emulsion was obtained by adding additional aqueous phase (II) (i.e., metal ions solution) in acetate buffer $\mathrm{pH} 4.7(28 \mathrm{~mL})$ to an organic phase composed of VP $(1.34 \mathrm{~g})$, TMPMA (10.00 g), AN (13.00 g), MBA (1.8 g), surface active monomer 4-vinyloxybutylstearate (VOBS; 0.3-0.8 wt.\%), cyclohexanol (CH, $48 \mathrm{~mL}$ ), and AIBN (1g) (Figure 4). Two types of emulsification system were used to prepare surface imprinted polymers. In modular system (KP), the prepared organic mixture was put through membrane module Amicon
8200. In sonication system (KPS), the mixture was sonicated for $40 \mathrm{~s}$ in pulsing mode using ultrasonic processor Sonics VCX-500 with standard probe. After emulsification, the prepared $\mathrm{W} / \mathrm{O}$ emulsion was added at $60^{\circ} \mathrm{C}$ to the aqueous phase that contained sodium dodecylsulfate (SDS). In these studies, four KO-polymers (with $\mathrm{Cu}(\mathrm{II}), \mathrm{Co}(\mathrm{II}), \mathrm{Zn}(\mathrm{II})$, and $\mathrm{Mn}(\mathrm{II})$ ions) and two $\mathrm{KP}$ (with $\mathrm{Cu}(\mathrm{II})$ and $\mathrm{Co}(\mathrm{II})$ ions) were synthesized.

The obtained polymer beads were washed with hot distilled water, acetone, AcO : EtOH mixture $(1: 1)$, EtOH, EtOH:distilled water mixture $(1: 1)$ in order to remove porogen, template, and impurities. Then, in order to remove metal ions from polymer matrix $1 \mathrm{M} \mathrm{HCl}$ solution was used until colourless solution was seen and no color change was observed in polymer washing solution in the test with concentrated ammonia solution $\left(\mathrm{NH}_{3} \cdot \mathrm{H}_{2} \mathrm{O}\right)$.

Additionally, two control polymers were obtained in the same manner as volumetric imprinted polymers, without 4VP and template.

2.2. Swelling Ratio of Imprinted Polymers (in Water, W, and Hydrochloric Acid, HC). The water and hydrochloric acid swelling ratio (W, $\mathrm{HC}(\mathrm{g} / \mathrm{g})$ ) was measured using centrifugation technique $(5 \mathrm{~min}, 3000 \mathrm{rpm})$ on Centrifuge MPW360. Approximately $1 \mathrm{~g}$ of polymer was placed in sintered glass column and washed with distilled water (or $0.001 \mathrm{M}$ hydrochloric acid) until the appropriate $\mathrm{pH}$ was obtained. Subsequently, polymer was centrifuged in the centrifugation vials to remove excess of solvent, placed in the glass vessel and dried till no changes of mass were observed.

2.3. Amino Groups and Nitrogen Content in MIPs. The amino groups content $\left(Z_{\mathrm{NH}_{2}}\right)$ was checked according to the modified Volhard method as chlorides attached to the amino groups. The sample of polymer was washed with $0.001 \mathrm{M}$ $\mathrm{HCl}$, centrifuged and placed in sintered glass column. $200 \mathrm{~mL}$ of $\mathrm{Na}_{2} \mathrm{SO}_{4}(4 \%)$ and $50 \mathrm{~mL}$ of distilled water were passed through the column and the filtrate was collected in the volumetric flask. The chlorides were first precipitated with 
<smiles>C=Cc1ccncc1</smiles><smiles>C=CC#N</smiles>

4-Vinylpyridine (VP)<smiles>COc1ccc(CO)cc1</smiles>

4-Methoxybenzyl alcohol (MBA)<smiles>C=C(C)C(=O)OCC(CC)(COC)COC(=O)C(=C)C</smiles>

Trimethylolpropane trimethacrylate (TMPMA)<smiles>C=COCCCCOC(=O)CCCCCCCCCCCCCCCCC</smiles>

4-Vinyloxybutylstearate (VOBS)

FIgUre 4: Compounds used during the polymerization.

excess of $0.1 \mathrm{M}$ silver nitrate, and then the excess of silver was titrated back with ammonium thiocyanate in the presence of ammonium iron sulfate.

Nitrogen content was analyzed according to Kjeldahl method. The known amount of the polymers (approximately $0.2 \mathrm{~g}$ ) was mineralized in the glass tubes using concentrated sulfuric acid, potassium sulfate, and copper sulfate. After that, the samples were diluted with distilled water and treated with $33 \%$ sodium hydroxide and ammonia was distilled off using Buchi Distillation Unit K-314. Ammonia was collected in solution of boric acid in the presence of indicators (methyl red and bromocresol green). Final solution was titrated with $0.1 \mathrm{M}$ hydrochloric acid.

2.4. Surface Morphology and Structure Characteristic of MIPs. The surface area and porosity measurements were performed using Micromeritics ASAP 2020 nitrogen sorption porosimeter. All samples before analysis were degassed for 12 hours under vacuum at $50^{\circ} \mathrm{C}$. Physisorption of nitrogen was carried out at liquid nitrogen temperature. All parameters were evaluated using Brunauer-Emmett-Teller (BET) equation. To confirm structure of the synthesized polymers, scanning electron microscopy (SEM) was carried out using a EVO LS15 Zeiss microscope. All samples were coated with gold prior to imaging. Presence of functional groups was confirmed by FTIR spectra obtained using PERKIN ELMER System 2000 FTIR.

2.5. Sorption of Metal Ions. Sorption of metals ions was carried out using batch method. Samples were placed into polyethylene containers and definite volume of metal acetate solution in acetate buffer ( $\mathrm{pH} 5)$ was added. Concentrations of metal acetate solution were chosen from the range $1 * 10^{-4}$ $5 * 10^{-3} \mathrm{M}$ depending on theoretical amino group's content.

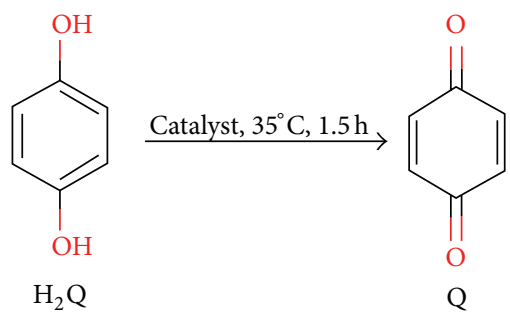

FIGURE 5: Hydroquinone oxidation reaction.

The samples were shaken for 48 hours. Subsequently, polymers were separated from the solution by filtration. The amount of metals in polymeric catalysts was measured by atomic absorption spectroscopy using GBC Avanta ASA spectrometer and calculated as a difference in the solution concentrations before and after sorption. The polymers were washed with distilled water and dried. Amount of metals ions were defined as metal loading $S_{\mathrm{M}(\mathrm{II})}(\mathrm{mmol} / \mathrm{g})$ per 1 gram of dry polymer.

\subsection{Evaluation of Catalytic Activity of Prepared Polymers.} The catalytic activity of KO (volumetric imprinting), KP, and KPS (surface imprinting) was examined in oxidation reaction of hydroquinone $\left(\mathrm{H}_{2} \mathrm{Q}, 4 * 10^{-4} \mathrm{M}\right)$ in the presence of the hydrogen peroxide solution in acetate buffer $(\mathrm{pH}$ ) (Figure 5).

The polymer catalysts were placed in the glass flask with substrate and hydrogen peroxide solution and shaken at a constant temperature $\left(35^{\circ} \mathrm{C}\right)$ for 1.5 hour in water bath (Elpin + Water Bath Shaker 357). The catalytic activity was determined spectrophotometrically using spectrophotometer UV-VIS Jasco 570c by monitoring an absorbance decrease 
for substrate and increase for product at $246 \mathrm{~nm}$ and $289 \mathrm{~nm}$, respectively.

For complete evaluation of catalytic activity of obtained materials, the reactions were carried out separately in the presence of imprinted polymers with no metal ions in their cavities, metal ion solution, and hydrogen peroxide solution.

The results of reaction are expressed as oxidation degree of substrate $\left(L_{\mathrm{H}_{2} \mathrm{Q}}(\%)\right)$, yield of product $\left(Y_{\mathrm{Q}}(\%)\right)$, and selectivity of product $\left(L_{\mathrm{Q}}(\%)\right)$ and calculated from the following expressions:

$$
\begin{gathered}
L_{\mathrm{H}_{2} \mathrm{Q}}[\%]=\frac{\left[\mathrm{H}_{2} \mathrm{Q}\right]_{t}}{\left[\mathrm{H}_{2} \mathrm{Q}\right]_{0}} \cdot 100, \quad Y_{\mathrm{Q}}[\%]=\frac{[\mathrm{Q}]_{t}}{\left[\mathrm{H}_{2} \mathrm{Q}\right]_{0}} \cdot 100, \\
S_{\mathrm{Q}}[\%]=\frac{[\mathrm{Q}]_{t}}{\left[\mathrm{H}_{2} \mathrm{Q}\right]_{t}} \cdot 100,
\end{gathered}
$$

where $\left[\mathrm{H}_{2} \mathrm{Q}\right]_{0, t}$ are initial substrate concentration and substrate concentration after time $t(\mathrm{~min})$, respectively; $[\mathrm{Q}]_{t}$ is product concentration after time $t(\mathrm{~min})$.

2.7. Imprinted Systems Stability Studies. Stability studies of obtained MIPs were also performed. Analysis consists of sorption process (10 months after synthesis) and catalysis depending on loading time. Subsequently, obtained polymers were used in oxidation reactions and the results were compared with the catalytic activity of polymers loaded with metal ions just after synthesis. Additionally, the catalytic activity for the same sample was checked after 10 and 18 months from polymerization.

\section{Results and Discussion}

Molecularly imprinted polymers were obtained in the suspension polymerization process using two methods: the surface and the volumetric imprinting. The mixture was composed of main complexing monomer (4-VP), neutral monomer $(\mathrm{AN})$ in a molar ratio of 0.05 , and $40 \mathrm{wt} \%$ of multifunctional crosslinking agent (TMPMA). In addition, in surface imprinting the functional surfactant was used (4VOBS) for enhancing the stability of prepolymerization emulsion, in an amount corresponding to $1.6 \mathrm{wt} \%$ of the prepared organic phase (monomers, crosslinking agent, metal acetate, porogen, template). Nine MIPs were synthesized using four types of transition metal performing important functions in biological systems:

(i) copper(II) ions in the form of $\mathrm{Cu}\left(\mathrm{CH}_{3} \mathrm{COO}\right)_{2} \cdot \mathrm{H}_{2} \mathrm{O}$, the volume and surface molecular imprinting (membrane and sonication system),

(ii) cobalt(II) ions in the form of $\mathrm{Co}\left(\mathrm{CH}_{3} \mathrm{COO}\right)_{2} \cdot 4 \mathrm{H}_{2} \mathrm{O}$, the volume and surface molecular imprinting,

(iii) manganese(II) ions in the form of $\mathrm{Mn}\left(\mathrm{CH}_{3} \mathrm{COO}\right)_{2}$. $4 \mathrm{H}_{2} \mathrm{O}$, the volume and surface molecular imprinting (sonication systems),

(iv) zinc(II) ions in the form of $\mathrm{Zn}\left(\mathrm{CH}_{3} \mathrm{COO}\right)_{2} \cdot 2 \mathrm{H}_{2} \mathrm{O}$, the volume molecular imprinting.
Manganese(II) and zinc(II) ions were used only in volumetric imprinting due to the poor stability of the formed metalmonomer complexes comparing to other ions. Their poor stability caused also separation of phases during the oil phase passing through the membrane system.

The aim of the 4-VP introduction as a functional monomer was to create an acid-base interactions between imprinted metal ions (intermediate Lewis acid) and the pyridine nitrogen atom (weak base). To obtain the system similar to porphyrin system more than 4 -fold, molar excess of 4-VP with respect to the metal ions was used. However, it was difficult to obtain porphyrin-like same system due to the formation of VP homopolymers. According to previous studies, the most effective active sites consist of metal ions coordinated by two pyridine group $-\mathrm{N}_{2} \mathrm{O}_{2}$ type (two other coordination sites are probably occupied by water) [22].

Addition of $\mathrm{AN}$ as a second functional monomer was aimed at facilitating the formation of the porous structure of the polymer in the presence of poor polar solvent (porogen), cyclohexanol. The introduction of $40 \mathrm{wt} \%$ of multifunctional crosslinker (TMPMA) allowed for more efficient binding of monomers and gave sufficient matrix flexibility. Methoxybenzyl alcohol (MBA) that shows some structural similarity to reagents was used as template. Simultaneously, using that compound also eliminated the inhibition of catalytic sites, which is usually observed when either substrate or product of the reaction is used as a template.

3.1. Physicochemical Properties of Imprinted Polymers. Determination of water $(\mathrm{W}(\mathrm{g} / \mathrm{g}))$ and $0.001 \mathrm{M} \mathrm{HCl}(\mathrm{HCl}(\mathrm{g} / \mathrm{g}))$ absorption was performed. The contents of amino groups (B $(\mathrm{mmol} / \mathrm{g}))$ and nitrogen $(\mathrm{N}(\mathrm{mmol} / \mathrm{g}))$ were compared with the theoretical quantity $\left(T_{\mathrm{N}}(\mathrm{mmol} / \mathrm{g})\right)$ introduced into the matrix in the polymerization process (Table 1 ).

All synthesized polymers were characterized by a similar water and $0.001 \mathrm{M} \mathrm{HCl}$ acid absorption, which is a confirmation of the reproducibility of the influence of porogenic solvent and suitable rigidity of matrix caused by AN on the porosity of the polymer matrix.

Any differences in water absorption between successive imprints may be the result of the impact of different metals on the structure of the cavity. At the same time, polymers prepared by surface molecular imprinting show higher water and $\mathrm{HCl}$ absorption in comparison to volumetric imprinted polymers. Better results for the catalysts prepared by the surface imprinting are explained by the greater availability of the cavities arranged on the surface of the polymer matrix and not in the interior.

It can be seen (in Table 1) that nitrogen content for polymers synthesized with copper ions is lower than that for other polymers. To explain that phenomena two control polymerizations were performed. Polymers obtained without presence of copper acetate possess higher nitrogen content than one with metal acetate. It means that copper acetate plays role of initiator for anionic polymerization and some part of AN polymerized to homopolymer and is removed from the polymeric matrix during cleaning step. 
TABLE 1: Physical and chemical properties of obtained MIPs.

\begin{tabular}{|c|c|c|c|c|c|c|c|}
\hline & $\mathrm{W}(\mathrm{g} / \mathrm{g})$ & $\mathrm{HCl}(\mathrm{g} / \mathrm{g})$ & $\mathrm{B}(\mathrm{mmol} / \mathrm{g})$ & $T_{\mathrm{B}}(\mathrm{mmol} / \mathrm{g})$ & $\mathrm{N}(\mathrm{mmol} / \mathrm{g})$ & $\mathrm{N}(\%)$ & $T_{\mathrm{N}}(\mathrm{mmol} / \mathrm{g})$ \\
\hline $\mathrm{KO}-\mathrm{Cu}(\mathrm{II})$ & 2.19 & 2.11 & 0.82 & \multirow{8}{*}{0.52} & 6.32 & 58.85 & \multirow{8}{*}{10.74} \\
\hline $\mathrm{KP}-\mathrm{Cu}(\mathrm{II})$ & 2.74 & 2.76 & 1.15 & & 2.10 & 19.55 & \\
\hline KPS-Cu(II) & 2.25 & 2.27 & - & & 4.55 & 42.36 & \\
\hline KO-Co(II) & 1.89 & 1.93 & 1.25 & & 6.47 & 60.24 & \\
\hline KP-Co(II) & 2.23 & 2.67 & 0.22 & & 6.48 & 60.34 & \\
\hline KO-Mn(II) & 2.06 & 2.08 & 0.19 & & 7.16 & 66.67 & \\
\hline KPS-Mn(II) & 2.50 & 2.62 & 0.19 & & 4.83 & 44.97 & \\
\hline KO-Zn(II) & 1.82 & 1.82 & 0.24 & & 6.14 & 57.17 & \\
\hline
\end{tabular}

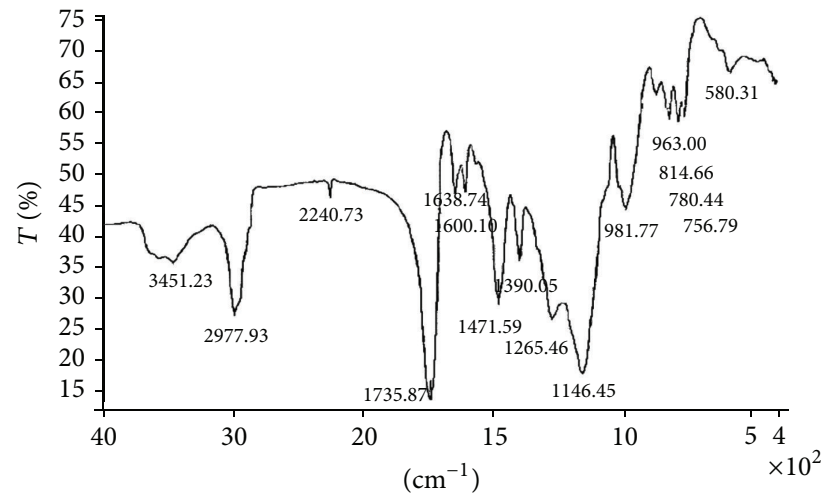

FIGURE 6: FT-IR spectrum for KPS-Cu.

3.2. Surface Morphology and Structure Characteristic of MIPs. The results of FTIR analysis clearly indicate the similarity in the structure, composition, and the contribution of individual monomers of each catalyst. In all spectra, the strongest peak in the range $1690-1760 \mathrm{~cm}^{-1}$ indicates the presence of $\mathrm{C}=\mathrm{O}$ group of the ester group in TMPMA. Additionally, the intense band of asymmetric vibrations (stretching) from $\mathrm{C}-\mathrm{O}$ group of the ester bond can be seen $\left(1050-1300 \mathrm{~cm}^{-1}\right)$, as well as broad band attributed to the valence vibrations of the ester group -C-CO-O- in the range of $1100-1266 \mathrm{~cm}^{-1}$. The presence of $-\mathrm{CH}_{2}$ - groups is indicated by many peaks originating from asymmetric (ca. $2970 \mathrm{~cm}^{-1}$ ) and symmetric (ca. $2945 \mathrm{~cm}^{-1}$ ) stretching vibration, in-plane scissoring deformation vibration (ca. $1740 \mathrm{~cm}^{-1}$ ), and out-of-plane rocking deformation $\left(1180-1350 \mathrm{~cm}^{-1}\right)$. The nitrile groups $\mathrm{C} \equiv \mathrm{N}$ of the acrylonitrile mers are shown as clear peak ascribed to the valence vibrations around $2245 \mathrm{~cm}^{-1}$. Above $3000 \mathrm{~cm}^{-1}$, the valence vibrations originating from $\mathrm{C}-\mathrm{H}$ bond vinyl groups and the stretching bond in the aromatic ring of 4vinylpyridine are shown. The presence of the pyridine ring is also confirmed by the presence of $\mathrm{C}=\mathrm{N}$ valence vibration in the $1500-1750 \mathrm{~cm}^{-1}$ and out-of-plane twisting deformation vibration of $\mathrm{CH}$ bond in the pyridine ring $\left(690-770 \mathrm{~cm}^{-1}\right)$. In addition, twisting deformation vibrations of $\mathrm{CH}$ bond in the vinyl group in $675-995 \mathrm{~cm}^{-1}$ and the valence vibrations of $\mathrm{C}=\mathrm{C}$ in the range of $1610-1680 \mathrm{~cm}^{-1}$ can be distinguished (Figure 6).

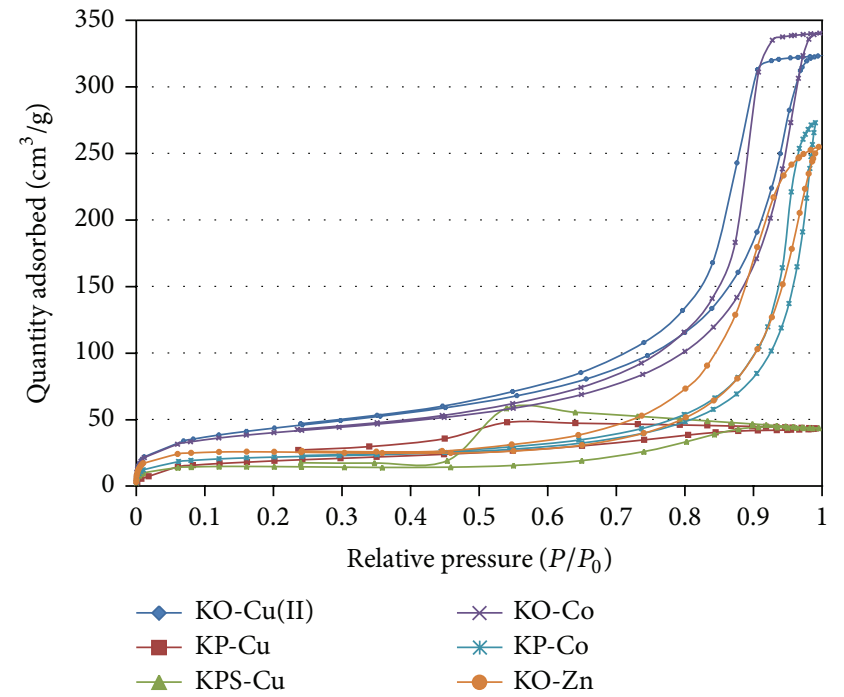

FIGURE 7: Nitrogen adsorptions and desorption isotherms obtained for MIPs.

Polymers were subjected to nitrogen sorption studies. The resultant isotherms demonstrated variation with respect to the kind of the metal ion introduced during the polymerization step, pore volume, pore area, and average pore width.

In particular, it was apparent that variation in the type of obtained imprinting $(\mathrm{KO} / \mathrm{KP})$ had a strong impact on the morphology of the resultant polymers, as seen by the differences in isotherm profiles for volumetric and surface imprinted polymers (Figure 7). Isotherms for $\mathrm{KO}-\mathrm{Cu}$ and KO-Co show big difference in the shape compared with $\mathrm{KP}-\mathrm{Co}$ and $\mathrm{KO}-\mathrm{Zn}$, which can be the result of various shapes of the pores. In addition, adsorption isotherm for $\mathrm{KP}-\mathrm{Cu}$ and KPS-Cu has completely different characteristics, which can be also seen in the lowest macro- and micropores volume (macropores: $\mathrm{KP}-\mathrm{Cu}-0.06 \mathrm{~cm}^{3} / \mathrm{g}$, KPS- $\mathrm{Cu}-$ $0.07 \mathrm{~cm}^{3} / \mathrm{g}$; micropores: $\mathrm{KP}-\mathrm{Cu}-0.010 \mathrm{~cm}^{3} / \mathrm{g}, \mathrm{KPS}-\mathrm{Cu}-$ $0.015 \mathrm{~cm}^{3} / \mathrm{g}$, as seen in Table 2). Surface area and pores volume are larger in the case of volumetric imprinting than those for surface imprinting (Table 2). Average pore size values are significantly lower than maximum pore size and are in the range of mesopores $(2-50 \mathrm{~nm})$. Additionally, micropores represent only $5 \%-7 \%$ of all pores (calculated from pores 
TABLE 2: Surface analysis obtained for MIPs.

\begin{tabular}{lcccccc}
\hline & KO-Cu & KP-Cu & KPS-Cu & KO-Co & KP-Co & KO-Zn \\
\hline Surface area $\left(\mathrm{m}^{2} / \mathrm{g}\right)($ by BET) & 138.07 & 58.24 & 42.22 & 136.53 & 70.11 & 106.65 \\
Average pore width (by BET) $[\AA]$ & 1802.79 & 1273.00 & 1313.06 & 1336.35 & 1119.41 & 1301.58 \\
Pore volume $\left(\mathrm{cm}^{3} / \mathrm{g}\right)$ & 0.48 & 0.06 & 0.07 & 0.52 & 0.38 & 0.45 \\
Median pore width (by Horvath-Kawazoe) $(\AA)$ & 139.20 & 39.43 & 63.67 & 153.04 & 218.44 & 172.09 \\
Maximum pore volume (by Horvath-Kawazoe) $\left(\mathrm{cm}^{3} / \mathrm{g}\right)$ & 0.033 & 0.010 & 0.015 & 0.033 & 0.019 & 0.030 \\
\hline
\end{tabular}

volume), only for $\mathrm{KP}-\mathrm{Cu}$ and $\mathrm{KPS}-\mathrm{Cu}$ it is approximately $18 \%$ and $22 \%$, respectively.

The SEM pictures show the difference in beads size and surface morphology of obtained polymers (Figure 8). It can be seen that surface imprinted polymers are characterized by smaller beads size (typical size 50-70 microns) than volumetric imprinted one (100 microns, for KO-Zn 300 microns) as emulsification of prepolymerization mixture results in fine dispersion of organic phase. Additionally, emulsification caused higher interfacial area between aqueous and organic phase and hence higher loss of AN to aqueous phase (lower nitrogen content in KP and KPS as seen in Table 1).

3.3. Sorption Characteristics of Metal Ions on MIPs. Sorption results for each catalytic system confirm the general dependency between initial solution concentration and metal uptake during sorption process: increase of metal solution concentration given to polymer samples influences positively metal loading of the active centers after sorption. Simultaneously, with an increase of molar ratio of amino groups to the metal ion $\left(Z_{\mathrm{NH}_{2}} / \mathrm{M}^{2+}\right)$, decrease of sorption capability can be seen (Figure 9). The highest metal uptake was obtained for the $\mathrm{KO}-\mathrm{Cu}(\mathrm{II})$.

\subsection{Catalytic Characteristics of Synthesized Enzyme Biomimics}

3.4.1. Catalytic Activity of Synthesized Polymers. The catalytic activity of the polymers was compared with the results of the reactions carried out in the presence of $\mathrm{H}_{2} \mathrm{O}_{2}$ solution, metal ions solution, and polymers without metal ions in the active sides. The results indicate that the catalysts with copper ions are the most efficient due to the formation of stable complex between template, metal ion, and functional monomers during polymerization step, causing precise pattering of the template. Furthermore, an appropriate stability of the complex is also a critical issue during uptaking of the substrate inside the catalytic sides. The obtained results reaffirm the Irving-Williams series of complex stability (Mn(II) $<\mathrm{Fe}$ (II) $<\mathrm{Co}(\mathrm{II})<\mathrm{Ni}(\mathrm{II})<\mathrm{Cu}(\mathrm{II})>\mathrm{Zn}(\mathrm{II}))$. As expected, catalysts with cobalt ions are characterized by lower catalytic activity than those with copper ions, but stronger than polymers with manganese and zinc ions. Even if the zinc complexes do not appear in biological systems for redox reactions, they exhibit some catalytic activity in biomimetic systems. For the catalysts with manganese ions, it was not possible to obtain any efficient catalytic activity due to the low loading in the cavities. On the other hand, manganese as a strong Lewis acid is not able to produce stable complex with pyridine ligands, which are medium Lewis base, which also may result in low activity.

For all synthesized polymers, reaction with MIP catalysts but without metal ions was carried out. In each case, the catalytic activity was higher for the polymers with metal ions. The biggest difference can be seen for $\mathrm{KP}-\mathrm{Cu}(\mathrm{II})$ and $\mathrm{KP}-\mathrm{Cu}(\mathrm{II})-\mathrm{BO}$ (without metal ions inside the cavities). It shows that the presence of the metal ions has crucial effect on the activity. The "surface imprinted polymers" provide better results for the oxidation process of the $\mathrm{H}_{2} \mathrm{Q}$ than the "volumetric imprinted polymers" for the same metal ion and similar loading (Figure 10). Additionally, the plot of substrate concentration versus reaction time for KO polymers shows necessity of substrate diffusion through polymer matrix into the cavities that are not on the surface. It can be seen as a lower catalytic activity at the beginning of the reaction which is not a case for KP polymers as well as for metal ions solutions.

Comparing the results obtained for polymeric catalysts with the catalytic activity of the metal ions in solution in the same oxidation reaction, it can be said that the presence of the cavity increases the system ability to oxidize substrate. Copper ions are the most effective in the oxidation reaction but in their case also dimers or trimers of the product appeared shortly after reaction start. The peaks at wavelength characteristic for the dimers and substrate overlap with each other, which is seen as an apparent increase of the substrate concentration in the plots of reaction progress in time.

For each catalytic systems, reactions with the catalysts characterized by different metal loading in the active sides were performed. It was proved that there is a loading optimum that provides the highest catalytic activity (Figure 11). Higher loadings cause the active sides overlapping, while the lower loadings is not enough to obtain a proper number of catalytic centers. For the "volumetric imprinted polymers" with copper ions, it can be seen that in range 30-50 $(\mu \mathrm{mol} / \mathrm{g})$ there is no visible difference between catalytic activities. In the case of surface imprinted polymers with loading 29.99 $(\mu \mathrm{mol} / \mathrm{g})$ the catalytic activity is slightly higher than that for $50.64(\mu \mathrm{mol} / \mathrm{g})$. The same pattern can be observed for KP and KPS polymers.

3.4.2. The Stability of the Obtained Polymeric Catalysts. Polymers imprinted with zinc and copper ions show high stability, while systems with cobalt ions do not exhibit such characteristics. Both KO-Co(II) and KP-Co(II) did not show the catalytic activity after 10 months from the synthesis as well as not being possible to perform new sorption tests 


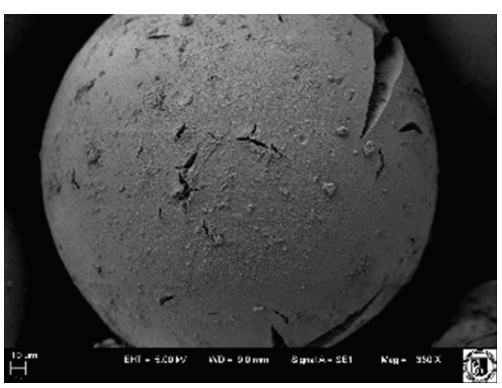

$\mathrm{KO}-\mathrm{Cu}(\mathrm{II})$

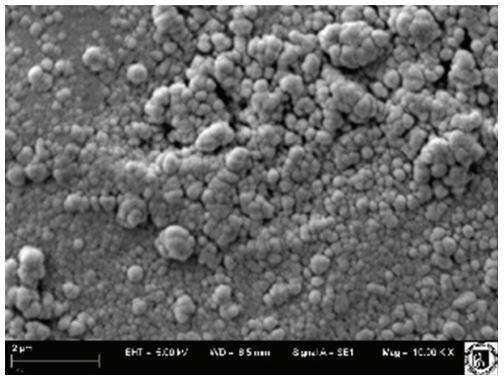

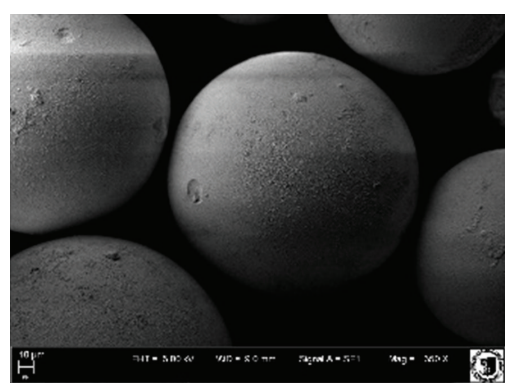

$\mathrm{KP}-\mathrm{Cu}(\mathrm{II})$

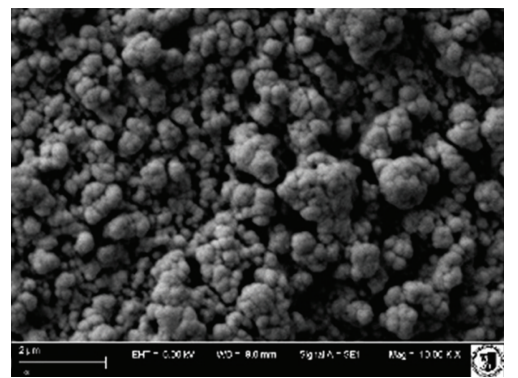

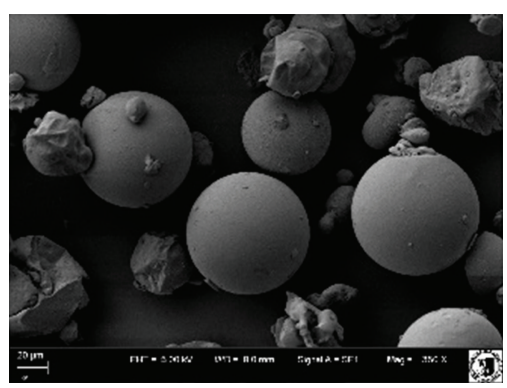

KPS-Cu(II)

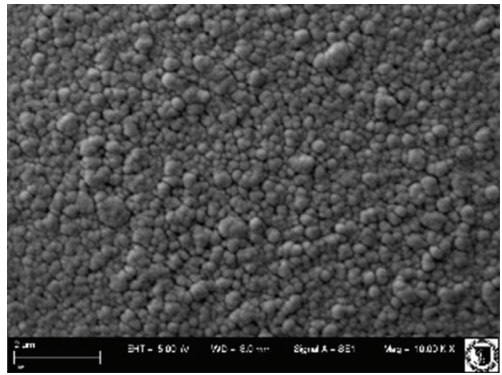

Figure 8: SEM pictures of KO-Cu, KP-Cu, and KPS-Cu.

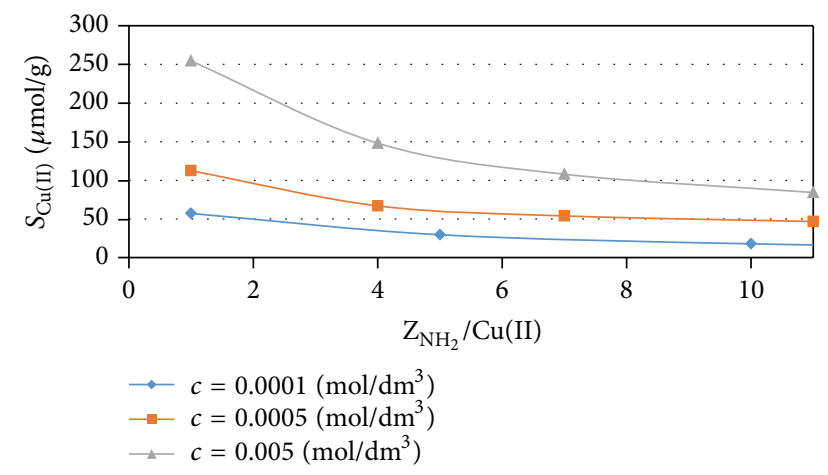

Figure 9: Comparison of sorption process versus molar ratio of amino groups to the copper ion in dependency of initial copper acetate concentration for KP-Cu.

of the metal ions using the samples left in a dry state for 10 months. For catalysts obtained with zinc and copper ions, both sorption and catalysis processes were successfully carried out in 10 and 18 months after polymerization and MIP polymers storage in a dry state (Figure 12).

\section{Conclusions}

The catalysts prepared using molecularly imprinted polymers with $\mathrm{Cu}$ (II) ions exhibited the highest activity in $\mathrm{H}_{2} \mathrm{Q}$ oxidation reactions compared to catalysts with other ions. For polymers synthesized with $\mathrm{Mn}$ (II) ions, it was not possible to obtain efficient loading. Using surface imprinting method with surface active monomer (4-VOBS), stabilized W/O emulsion was obtained during synthesis. Obtained active sites were distributed on the surface of pores, which eliminated the

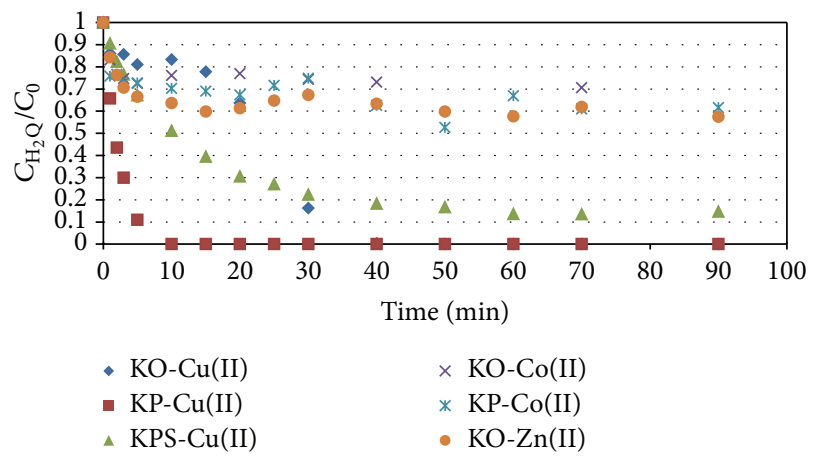

FIgURE 10: Comparison of oxidation reaction in dependency of metal ions inside the cavities.

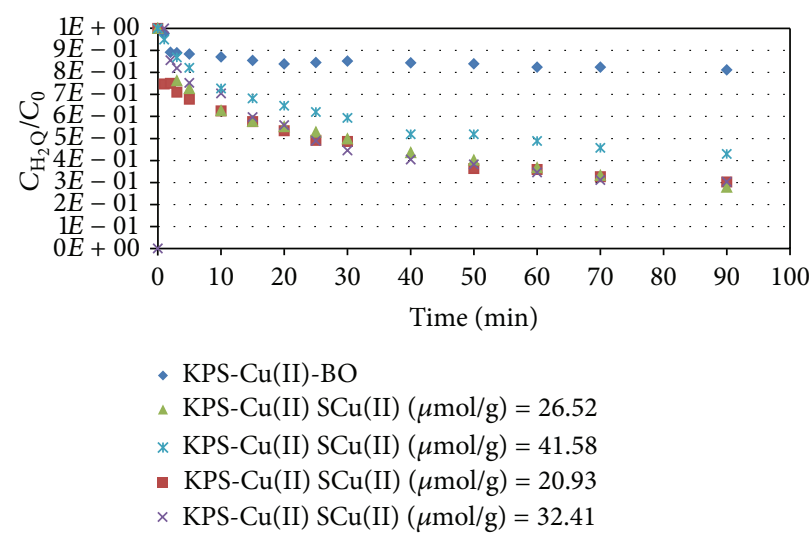

FIgURE 11: Comparison of oxidation reaction in dependency of loading value for KPS-Cu (KPS-Cu(II)-BO-catalysis without metal ions inside active sides). 


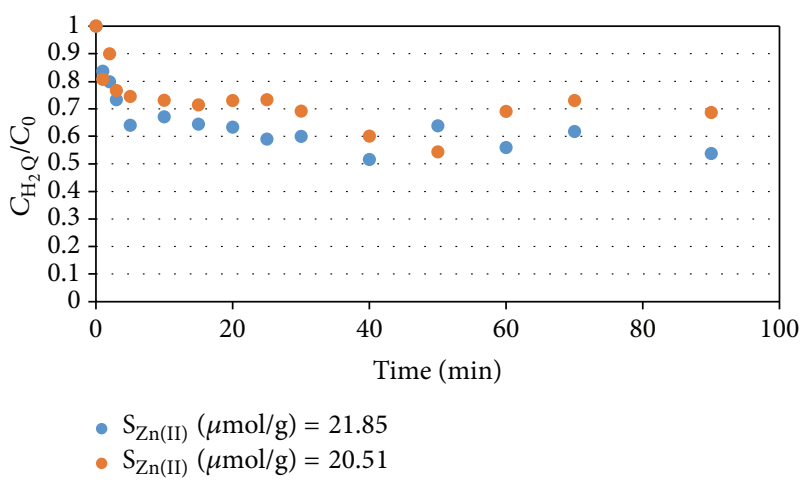

FIGURE 12: Comparison of oxidation reaction in dependency of loading time after polymerization for $\mathrm{KO}-\mathrm{Zn}$ (red plot-loading just after synthesis, blue plot-loading in 10 months after polymerization).

need for substrate diffusion into polymer matrix. For both catalysts with copper(II) and zinc(II) ions, the obtained beads were stable after keeping them in a dry state.

\section{Acknowledgment}

This work was financially supported by Wroclaw University of Technology Grant no. S20096/Z0309.

\section{References}

[1] A. Wolfgang, Enzymes in Industry, Production and Applications, Wiley-VCH, Weinheim, Germany, 2004.

[2] O. Kirk, T. V. Borchert, and C. C. Fuglsang, "Industrial enzyme applications," Current Opinion in Biotechnology, vol. 13, no. 4, pp. 345-351, 2002.

[3] S. A. Piletsky, N. W. Turner, and P. Laitenberger, "Molecularly imprinted polymers in clinical diagnostics-future potential and existing problems," Medical Engineering and Physics, vol. 28, no. 10, pp. 971-977, 2006.

[4] N. Holland, J. Frisby, E. Owens, H. Hughes, P. Duggan, and P. McLoughlin, "The influence of polymer morphology on the performance of molecularly imprinted polymers," Polymer, vol. 51, no. 7, pp. 1578-1584, 2010.

[5] Z. Cheng and Y. Li, "The role of molecular recognition in regulating the catalytic activity of peroxidase-like polymers imprinted by a reductant substrate," Journal of Molecular Catalysis A, vol. 256, no. 1-2, pp. 9-15, 2006.

[6] C. Alexander, H. S. Andersson, L. I. Andersson et al., "Molecular imprinting science and technology: a survey of the literature for the years up to and including 2003," Journal of Molecular Recognition, vol. 19, no. 2, pp. 106-180, 2006.

[7] S. A. Piletsky, S. Alcock, and A. P. F. Turner, "Molecular imprinting: at the edge of the third millennium," Trends in Biotechnology, vol. 19, no. 1, pp. 9-12, 2001.

[8] A. G. Mayes and M. J. Whitcombe, "Synthetic strategies for the generation of molecularly imprinted organic polymers," Advanced Drug Delivery Reviews, vol. 57, no. 12, pp. 1742-1778, 2005.

[9] H. Yan and H. R. Kyung, "Characteristic and synthetic approach of molecularly imprinted polymer," International Journal of Molecular Sciences, vol. 7, no. 5-6, pp. 155-178, 2006.
[10] D. R. Kryscio and N. A. Peppas, "Critical review and perspective of macromolecularly imprinted polymers," Acta Biomaterialia, vol. 8, no. 2, pp. 461-473, 2012.

[11] M. Tada and Y. Iwasawa, "Design of molecular-imprinting metal-complex catalysts," Journal of Molecular Catalysis A, vol. 199, no. 1-2, pp. 115-137, 2003.

[12] O. Ramstrom and R. J. Ansell, "Molecular imprinting technology: challenges and prospects for the future," Chirality, vol. 10, no. 3, pp. 195-209, 1998.

[13] S. Vidyasankar and F. H. Arnold, "Molecular imprinting: selective materials for separations, sensors and catalysis," Current Opinion in Biotechnology, vol. 6, no. 2, pp. 218-224, 1995.

[14] W. Li and S. Li, "Molecular imprinting: a versatile tool for separation, sensors and catalysis," Advances in Polymer Science, vol. 206, no. 1, pp. 191-210, 2007.

[15] C. Alexander, L. Davidson, and W. Hayes, "Imprinted polymers: artificial molecular recognition materials with applications in synthesis and catalysis," Tetrahedron, vol. 59, no. 12, pp. 20252057, 2003.

[16] J. D. Marty and M. Mauzac, "Molecular imprinting: state of the art and perspectives," Advances in Polymer Science, vol. 172, pp. $1-35,2005$.

[17] A. J. Hall, M. Emgenbroich, and B. Sellergren, Imprinted Polymers in Templates in Chemistry II, Springer, Berlin, Germany, 2005.

[18] G. Wulff, "Enzyme-like catalysis by molecularly imprinted polymers," Chemical Reviews, vol. 102, no. 1, pp. 1-28, 2002.

[19] N. Holland, An Investigation into the Role of Morphology on the Performance of Molecularly Imprinted Polymers, Waterford Institute of Technology, Waterford, Ireland, 2008.

[20] Z. Chen, L. Xu, Y. Liang, and M. Zhao, "PH-sensitive water-soluble nanospheric imprinted hydrogels prepared as horseradish peroxidase mimetic enzymes," Advanced Materials, vol. 22, no. 13, pp. 1488-1492, 2010.

[21] M. Yoshida, K. Uezu, F. Nakashio, and M. Goto, "Spacer effect of novel bifunctional organophosphorus monomers in metalimprinted polymers prepared by surface template polymerization," Journal of Polymer Science A, vol. 36, no. 15, pp. 2727-2734, 1998.

[22] B. N. Kolarz and A. Jakubiak, "Catalytic activity of molecular imprinted vinylpyridine/acrylonitrile/divinylbenzene terpolymers with guanidyl ligands- $\mathrm{Cu}(\mathrm{II})$ inside the active centres," Polimery, vol. 53, no. 11-12, pp. 848-853, 2008. 

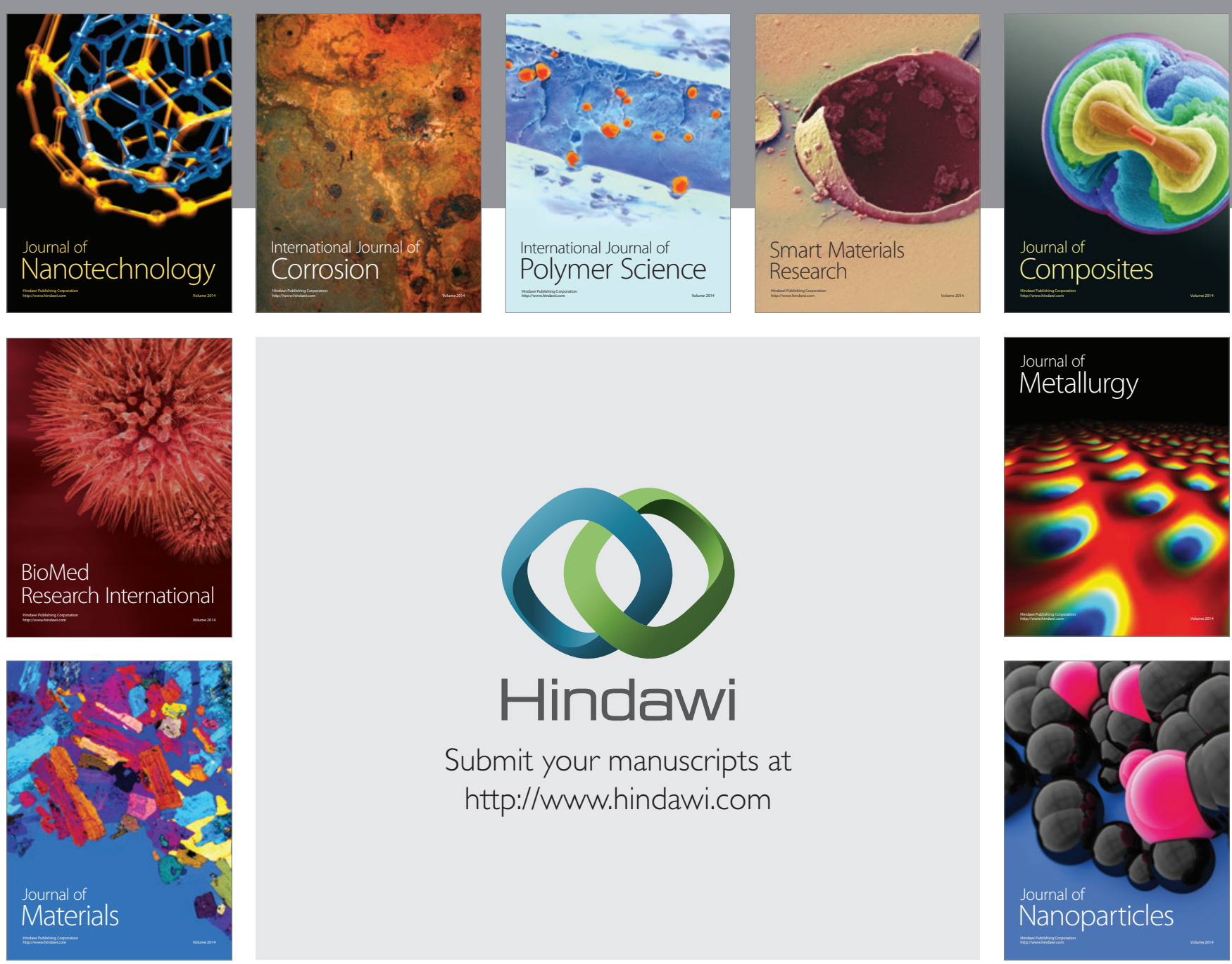

Submit your manuscripts at http://www.hindawi.com
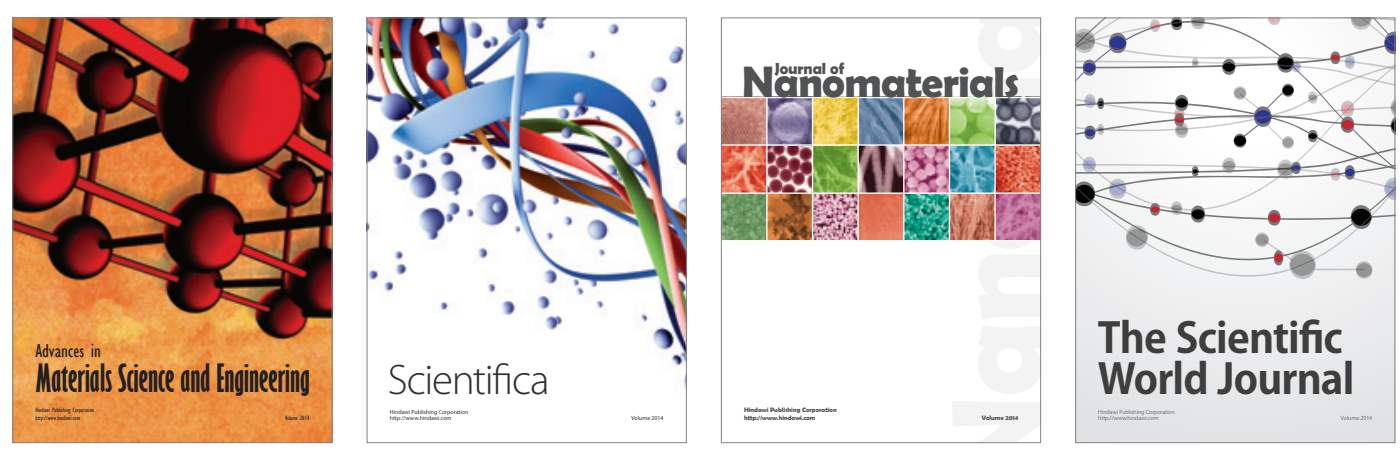

\section{The Scientific World Journal}
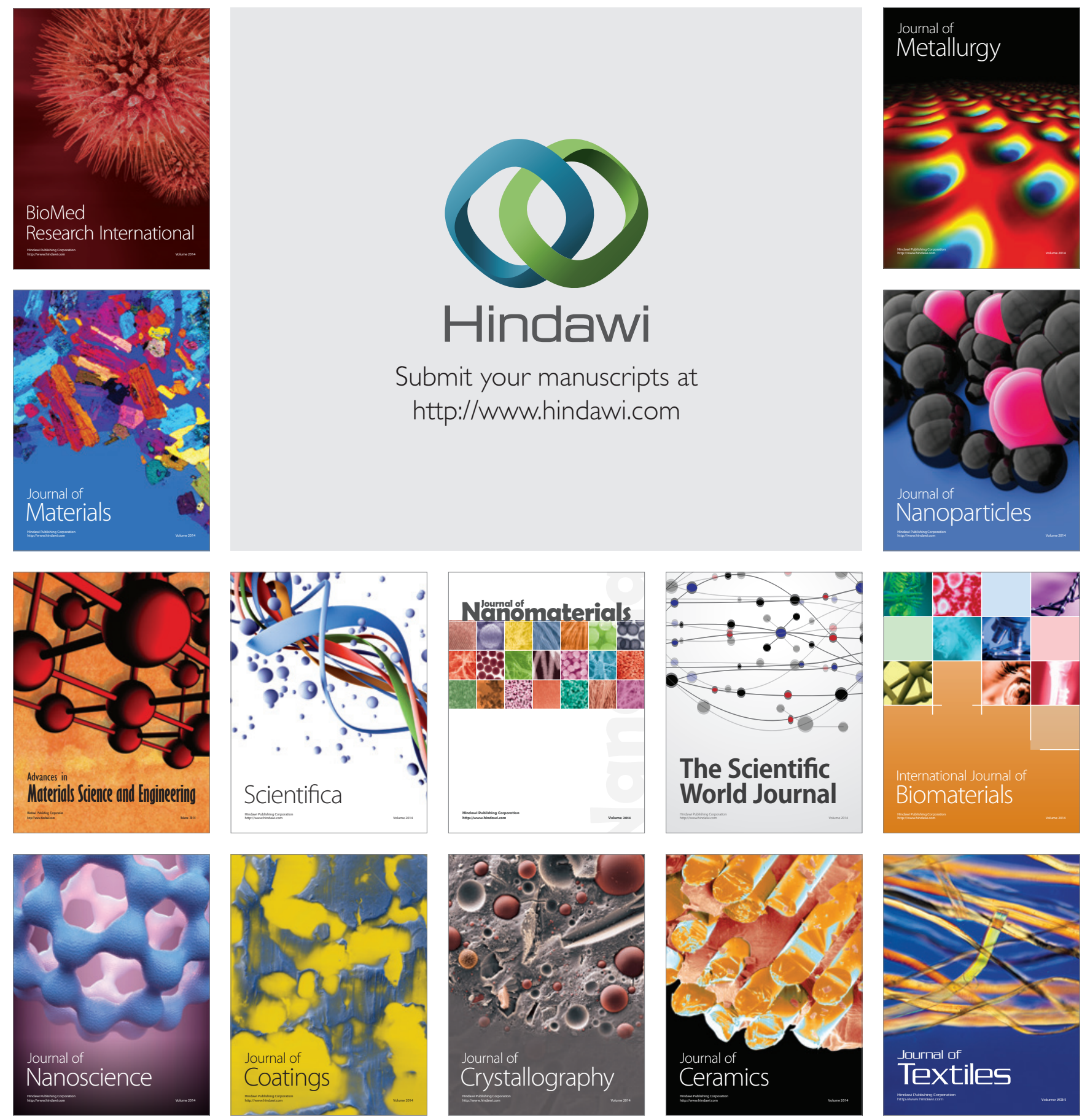